\title{
MicroRNA-1 upregulation promotes myocardiocyte proliferation and suppresses apoptosis during heart development
}

\author{
LIPING LIU ${ }^{1}$, YONGHUA YUAN ${ }^{1}, \mathrm{XUEHUA} \mathrm{HE}^{1}, \mathrm{XIAOHUI} \mathrm{XIA}^{2}$ and XIAOYANG MO ${ }^{3}$ \\ ${ }^{1}$ Department of Pediatrics, Children's Medical Center; ${ }^{2}$ Department of Ultrasonography, People's Hospital of Hunan, \\ Changsha, Hunan 410005; ${ }^{3}$ Faculty of Life Sciences, Hunan Normal University, Changsha, Hunan 410006, P.R. China
}

Received December 29, 2015; Accepted January 10, 2017

DOI: $10.3892 / \mathrm{mmr} .2017 .6282$

\begin{abstract}
Previous studies have investigated the role of microRNAs (miRs) in heart development to reveal the miRNA mechanism of action in congenital heart disease (CHD) in children. The present study aimed to investigate the role of miR-1 in heart development in P19 cells. The mRNA level for miR-1 in P19 cells was detected before or after cardiomyocyte differentiation, using reverse transcription-quantitative polymerase chain reaction analysis. Expression of cardiomyocyte differentiation markers was also analyzed. The effect of miR-1 overexpression on the viability and apoptosis of differentiated P19 cells was assessed using MTT and Annexin V-FITC assays, respectively. Furthermore, the effects of miR-1 on expression of markers of cell proliferation and apoptosis were also analyzed in differentiated P19 cells using western blotting. The results demonstrated that P19 cells were successfully differentiated into cardiomyocytes, and that endogenous miR-1 expression was significantly decreased in differentiated P19 cells compared with undifferentiated P19 cells. Overexpression of miR-1 resulted in increased viability in differentiated P19 cells and decreased apoptosis, compared with the normal control. In addition, expression of heart and neural crest derivatives expressed transcript 2 (Hand2) was increased in differentiated cells with miR-1 overexpressed compared with normal cells, while caspase-3 cleavage was decreased by miR-1 overexpression. In conclusion, the present study suggested that miR-1 upregulation may be important in regulating cell proliferation and apoptosis in P19 differentiated cardiomyocytes by increasing Hand 2 expression and suppressing caspase-3 cleavage. The present study aimed to provide a theoretical basis for the explanation of the mechanism
\end{abstract}

Correspondence to: Dr Liping Liu, Department of Pediatrics, Children's Medical Center, People's Hospital of Hunan, 61 Jiefang West Road, Changsha, Hunan 410005, P.R. China

E-mail: 190606755@qq.com

Key words: heart development, myocardiocytes, microRNA-1, P19 cells, cell proliferation, cell apoptosis of CHD and investigate miR-1 as a potential therapeutic target for its clinical treatment.

\section{Introduction}

Congenital heart disease (CHD) is one of the most common birth defects in humans worldwide, occurring in $\sim 7-8 \%$ of infants born annually (1). Improved surgical treatments have decreased the mortality of children with CHD, but not all infants with CHD survive to adulthood $(2,3)$. The mechanism of heart development is complex, and involves multiple genetic and environmental factors in its regulation (4). Therefore, investigations of relevant target genes and microRNAs (miRNAs) are important to fully comprehend the mechanism of heart development and to provide therapeutic targets for treatment of CHD in children.

miRNAs are endogenous non-coding RNAs of 20-22 nucleotides in length that have diverse functions in biological processes at the transcriptional or post-transcriptional level, by targeting the 3'-UTR of genes (5). Previous studies have revealed that miRNAs are involved in the development of the heart, including cardiomyocyte differentiation, cell cycle and the conducting system of the heart $(6,7)$. The muscle-specific miR-1 has been reported to be important in heart development. For example, miR-1 transcription is affected by the regulation of myogenic differentiation 1 (MyoD), myocyte enhancer factor (Mef), and serum response factor (SRF) (8). High levels of miR-1 expression in mice lead to cardiomyocyte cell cycle arrest at an early stage and attenuated cell proliferation $(9,10)$. The mouse teratoma-derived P19 cells are pluripotent, and thus can be differentiated into cardiomyocytes, skeletal muscle cells and neurons, allowing the application of P19 cells in cell replacement therapy and myocardial tissue engineering $(11,12)$. Although several studies have reported significant roles of miR-1 in regulating heart development in mice and in human cells, few have explored the possible role of miR-1 in regulating the heart development in P19 cells.

The present study aimed to investigate the role of miR-1 in heart development and to reveal a possible mechanism of action. Endogenous expression of miR-1 was assessed in P19 cells, as was the effect of miR-1 overexpression on the biological processes of P19 differentiated cardiomyocytes. In addition, the effect of miR-1 overexpression on cell viability and cell apoptosis-related protein expression was examined. 


\section{Materials and methods}

Cell culture and cell differentiation. P19 cells (American Type Culture Collection, Manassas, VA, USA) were cultured in Gibco $\alpha$-modified Eagle's medium ( $\alpha$-MEM; Thermo Fisher Scientific, Inc., Waltham, MA, USA) supplemented with $10 \%$ Gibco fetal bovine serum (FBS; Thermo Fisher Scientific, Inc.), $100 \mathrm{U} / \mathrm{ml}$ penicillin, and $100 \mu \mathrm{g} / \mathrm{ml}$ streptomycin at $37^{\circ} \mathrm{C}$ in $5 \% \mathrm{CO}_{2}$.

For the cardiac differentiation assay (13), $1 \times 10^{6}$ cells/ml P19 cells were plated onto $10 \mathrm{~cm}$ bacterial dishes in $15 \mathrm{ml} \alpha$-MEM containing 1\% dimethyl sulphoxide (DMSO; Sigma-Aldrich; Merck Millipore, Darmstadt, Germany), 10\% FBS, 100 U/ml penicillin, and $100 \mu \mathrm{g} / \mathrm{ml}$ streptomycin at $37^{\circ} \mathrm{C}$ in $5 \% \mathrm{CO}_{2}$. Following $96 \mathrm{~h}$ of incubation, cells were transferred onto $6 \mathrm{~cm}$ bacterial dishes and cultured in $\alpha$-MEM containing $10 \%$ FBS for another 6 days of incubation.

Cell transfection. The miRNA mimic (Gene ID: 100314077; Sangon Biotech Co., Ltd., Shanghai, China) was transfected into the differentiated P19 cells using the Lipofectamine ${ }^{\circledR} 2000$ protocol (Thermo Fisher Scientific, Inc.). Cells transfected with the scrambled RNA (catalog no. CS7005; Sangon Biotech, Co., Ltd.) were used as the control.

Cell proliferation assay. Cell proliferation ability was assessed using the 3-(4,5-dimethyl-2-thiazolyl)-2,5-diphenyltetrazolium bromide (MTT) assay, as previously described (14). Briefly, following transfection for $24 \mathrm{~h}, 5 \times 10^{3}$ cells were seeded into 96 -well plates. Following $24 \mathrm{~h}$ of incubation, cells cultured at $37^{\circ} \mathrm{C}$ were centrifuged at $4,000 \times g$ for $5 \mathrm{~min}$, and the supernatant was removed. MTT $(20 \mu \mathrm{l})$ was added into the cells and then cultured for another $4 \mathrm{~h}$. Finally, $150 \mu \mathrm{l}$ DMSO was mixed with the cells for $10 \mathrm{~min}$ to stop the reaction at room temperature. Absorbance of cells in each well was observed at $570 \mathrm{~nm}$ with an absorption spectrophotometer (Olympus Corporation, Tokyo, Japan).

Cell apoptosis assay. Apoptotic cells were measured using flow cytometry following staining with the Annexin V-FITC apoptosis kit (Invitrogen; Thermo Fisher Scientific, Inc.), according to the manufacturer's protocol. Briefly, following transfection for $36 \mathrm{~h}$, cells were cultured in fresh serum-free $\alpha$-MEM medium for $12 \mathrm{~h}$. Then total cells were harvested and washed 3 times with PBS buffer, followed by resuspension in the kit staining buffer. Then, $5 \mu \mathrm{l}$ of Annexin V-FITC and $5 \mu \mathrm{l}$ of propidium iodide (PI) were added into the cells at room temperature for $10 \mathrm{~min}$. Mixtures were analyzed using FACS can flow cytometry (BD Biosciences, Franklin Lakes, NJ, USA). The number of early-stage apoptotic cells (Annexin $\mathrm{V}^{+}$ and PI' cells) was then analyzed.

Reverse transcription-quantitative polymerase chain reaction $(R T-q P C R)$. Extraction of total RNA from cells was performed using TRIzol reagent (Invitrogen; Thermo Fisher Scientific, Inc.), according to the manufacturer's protocol. The extracted RNA was treated with RNase-free Dnase I (Promega Corporation, Madison, WI, USA) to remove the contaminating DNA, and concentration and purity were measured using SMA 400 UV-VIS (Merinton, Shanghai, China). Purified RNA
Table I. Primers used for target amplification.

\begin{tabular}{ll}
\hline Gene target & \multicolumn{1}{c}{ Sequence (5'-3') } \\
\hline GAPDH & F-GGGTGGAGCCAAACGGGTC \\
GATA4 & R-GGAGTTGCTGTTGAAGTCGCA \\
& F-CCTGCGGCCTCTACATGA \\
Nkx2-5 & F-AGGGTCTCACCAGCAGGA \\
& R-CCTGCGGCCTCTACATGA \\
Hand2 & F-TACCAGCTACATCGCCTACCT \\
& R-TCACTGCTTGAGCTCCAGGG \\
Caspase-3 & F-TACCCTGAAATGGGCTTGTGT \\
miR-1 & R-GTTAACACGAGTGAGGATGTG \\
& F-GTAGGCACCTGAAATGGAA \\
U6 & R-TTGATGGTGCCTACAGTACAT \\
& F-CGCTTCACGAATTTGCGTGTCAT \\
& R-AACGCTTCACGAATTTGCGT
\end{tabular}

F, forward; R, reverse; GATA4, GATA binding protein 4; Nkx2-5, NK2 homeobox 5; Hand2, heart and neural crest derivatives expressed transcript 2; miR-1, microRNA-1; U6, U6 small nuclear RNA.

dissolved in nuclease-free water at a concentration of $0.5 \mu \mathrm{g} / \mu \mathrm{l}$ was used for cDNA synthesis with the PrimerScript 1st Strand cDNA Synthesis kit (Invitrogen; Thermo Fisher Scientific, Inc.). Expression of targets was analyzed using an ABI 7900 (PE Applied Biosystems; Thermo Fisher Scientific, Inc.) and the SYBR ExScript RT-PCR kit (Takara Biotechnology Co., Ltd., Dalian, China). GAPDH was selected as the internal control for target gene expression, U6 small nuclear RNA (U6) was used as the internal control for the miRNA expression. Primers used for target amplification are listed in Table I (15).

Western blotting. Cells were lysed with radioimmunoprecipitation assay buffer at $4^{\circ} \mathrm{C}$ for $5 \mathrm{~min}$ (RIPA; Sangon Biotech Co., Ltd.) containing phenylmethylsulfonyl fluoride (PMSF; Sigma-Aldrich; Merck Millipore), and then were centrifuged at $4,000 \times \mathrm{g}$ at $4^{\circ} \mathrm{C}$ for $10 \mathrm{~min}$. Protein concentration was detected using a bicinchoninic acid assay kit (Pierce; Thermo Fisher Scientific, Inc.). For western blotting, total protein (30 $\mu \mathrm{l}$ ) was subjected to $12 \%$ SDS-PAGE, followed by transfer onto a polyvinylidenefluoride (PVDF) membrane. The PVDF membranes were blocked with TBS/0.1\% Tween-20 (TBST) buffer containing 5\% non-fat milk at room temperature for $1 \mathrm{~h}$. Then the membranes were incubated with rabbit primary antibodies against heart and neural crest derivatives expressed 2 (Hand 2; 1:100; catalog no. ab10131; Abcam, Cambridge, MA, USA), caspase-3 (1:100; catalog no. ab2171), cleaved caspase-3 (1:100; catalog no. ab13585) or GAPDH (1:100; catalog no. ab8245) obtained from Invitrogen; Thermo Fisher Scientific, Inc., overnight at $4^{\circ} \mathrm{C}$, then horseradish-peroxidase labeled goat anti-rat secondary antibody (catalog no. ab7097; 1:1,000; Abcam) at room temperature for $1 \mathrm{~h}$. Finally, the PVDF membranes were washed 3 times with TBST buffer for 10 min each wash. Signals were detected following incubation 


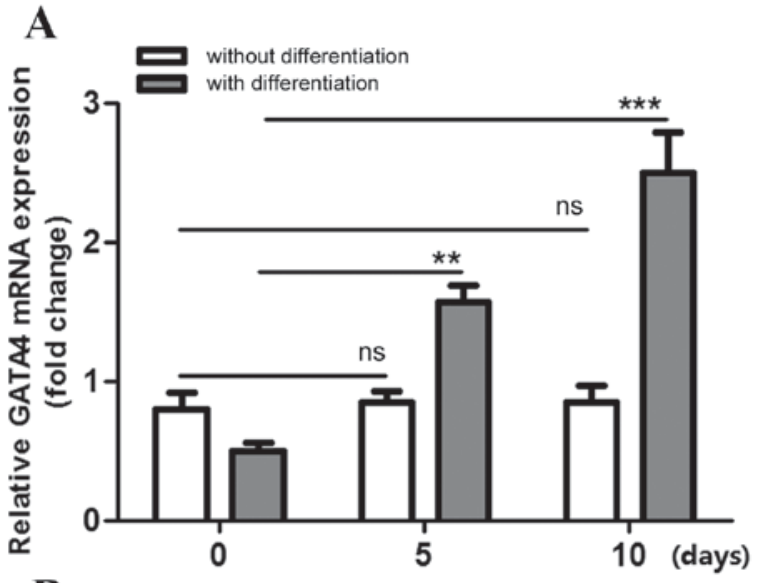

B

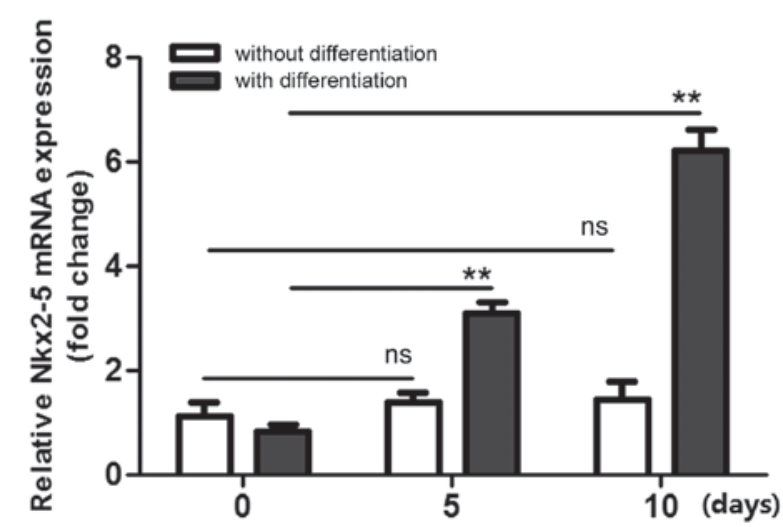

Figure 1. Cell differentiation for P19 cells. mRNA expression levels for (A) GATA4 and (B) Nkx2-5 were measured at 0,5 and 10 days following differentiation treatment in P19 cells by reverse transcription-quantitative polymerase chain reaction, with GAPDH as an internal control. Untreated, undifferentiated cells were used as a control. ${ }^{* *} \mathrm{P}<0.01$ and ${ }^{* * * *} \mathrm{P}<0.001$, with comparisons indicated by lines. GATA4, GATA binding protein 4; Nkx2-5, NK2 homeobox 5; ns, no significant difference.

with a chromogenic substrate using an enhanced chemiluminescence kit (Sigma-Aldrich; Merck Millipore). GAPDH served as the internal control.

Statistical analysis. Data are presented as the mean \pm standard deviation of 3 independent replicates. Statistical analysis between two groups was performed using a t-test, whereas the multiple comparisons were analyzed by post-hoc tests that followed one-way analysis of variance. All significant differences were analyzed using SPSS 19.0 statistical software (IBM SPSS, Armonk, NY, USA). P $<0.05$ was considered to indicate a statistically significant difference.

\section{Results}

Cell differentiation of P19 cells. Firstly, successful differentiation of P19 cells into cardiomyocytes was established. Following treatment with DMSO, mRNA expression levels of the cardiomyocyte differentiation markers GATA binding protein 4 (GATA4; Fig. 1A) and NK2 homeobox 5 (Nkx2-5; Fig. 1B) were analyzed. The results demonstrated that the relative mRNA expression levels for GATA4 and Nkx2-5 in the cells increased in a time-dependent manner for the whole duration of the 10 days of differentiation treatment, compared
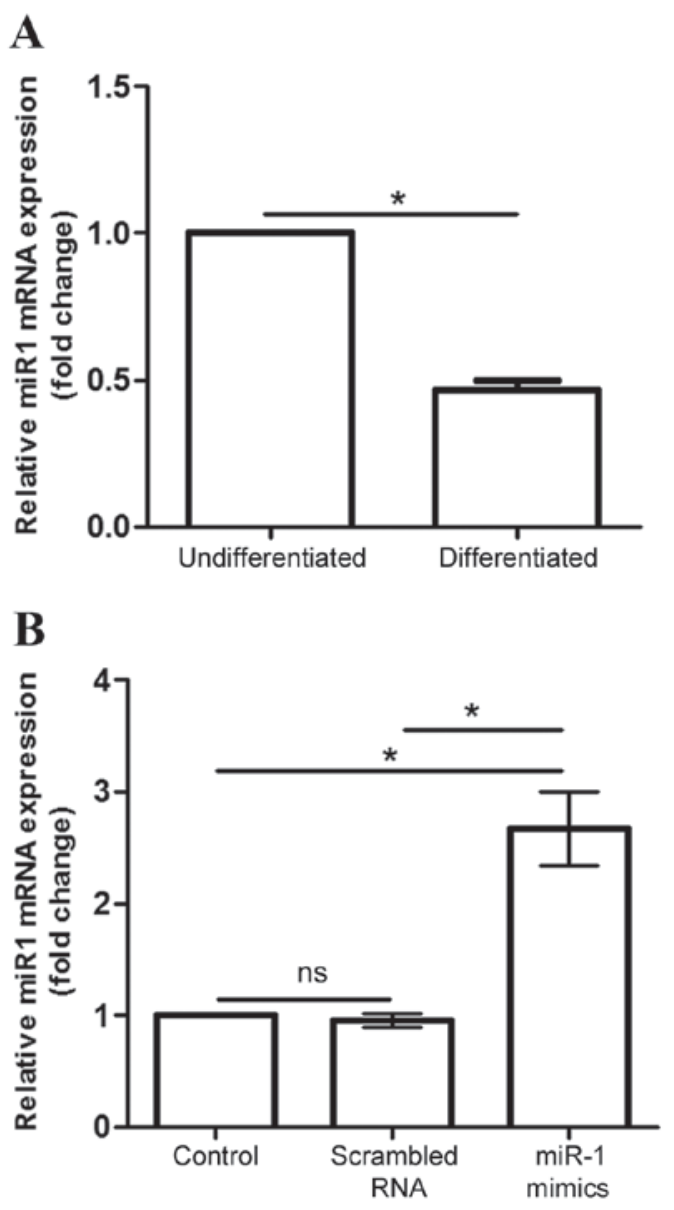

Figure 2. Expression of miR-1 in P19 cells. Expression was analyzed by reverse transcription-quantitative polymerase chain reaction, with U6 small nuclear RNA as the internal control. (A) Expression of endogenous miR-1 in differentiated P19 cells relative to undifferentiated cells. (B) Expression of miR-1 in differentiated P19 cells transfected with either scrambled RNA or miR-1 mimics relative to untransfected control cells. " $\mathrm{P}<0.05$, with comparisons indicated by lines. miR-1, microRNA-1; ns, not significant.

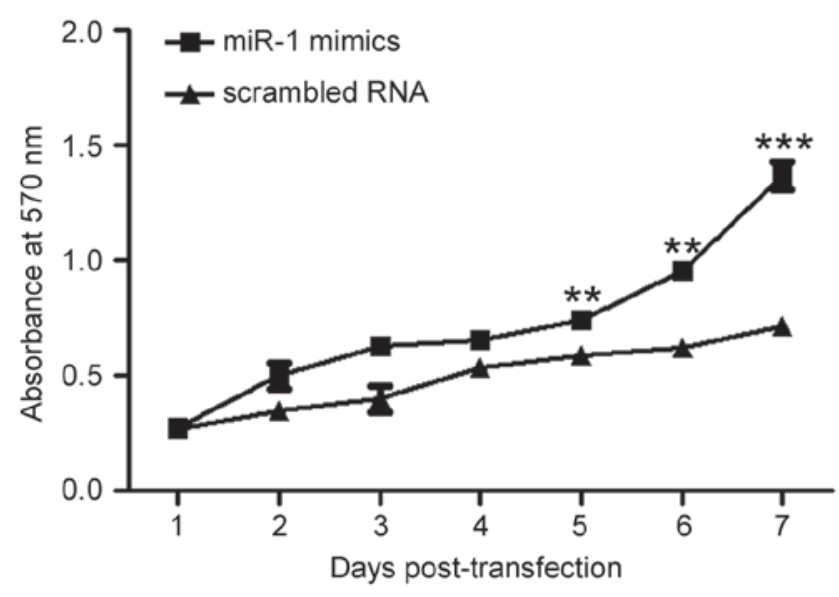

Figure 3. Effects of miR-1 overexpression on differentiated P19 cell viability. Differentiated P19 cells were transfected with either scrambled RNA or miR-1 mimics, and cell viability was assessed by MTT assay. miR-1, microRNA-1. ${ }^{* * *} \mathrm{P}<0.01,{ }^{* * *} \mathrm{P}<0.001$ vs. control cells transfected with scramble RNA.

with that at day 0 (Fig. 1). However, their levels in the undifferentiated P19 cells were not significantly different to $t=0$ at 
A

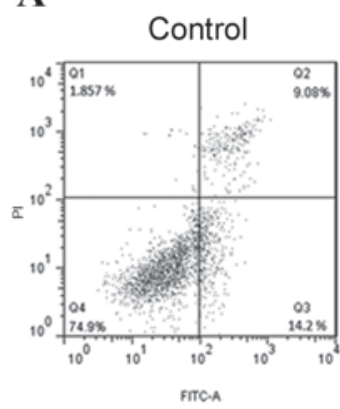

Scrambled RNA

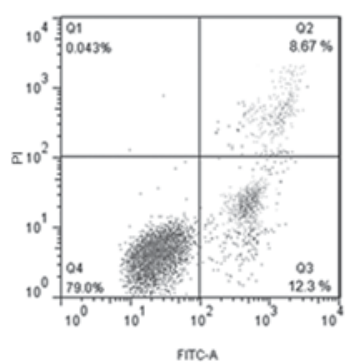

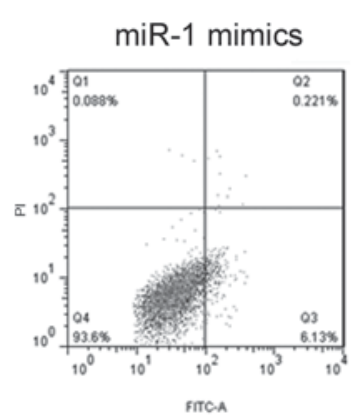

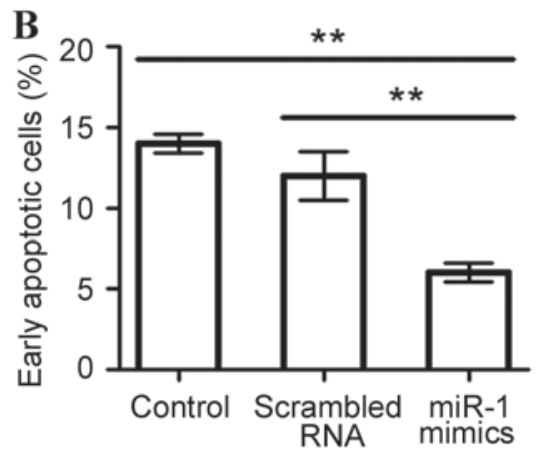

Figure 4. Effect of miR-1 overexpression on apoptosis in differentiated P19 cells. Differentiated P19 cells were untransfected, or transfected with either scrambled RNA or with miR-1 mimics, and apoptosis was measured by Annexin V-FITC/PI staining and flow cytometry. (A) Representative images from the flow cytometry analysis. (B) Quantification of early-stage apoptotic cells. ${ }^{* *} \mathrm{P}<0.01$, with comparisons indicated by lines. miR-1, microRNA-1; FITC, fluorescein isothiocyanate; PI, propidium iodide.

$\mathbf{A}$

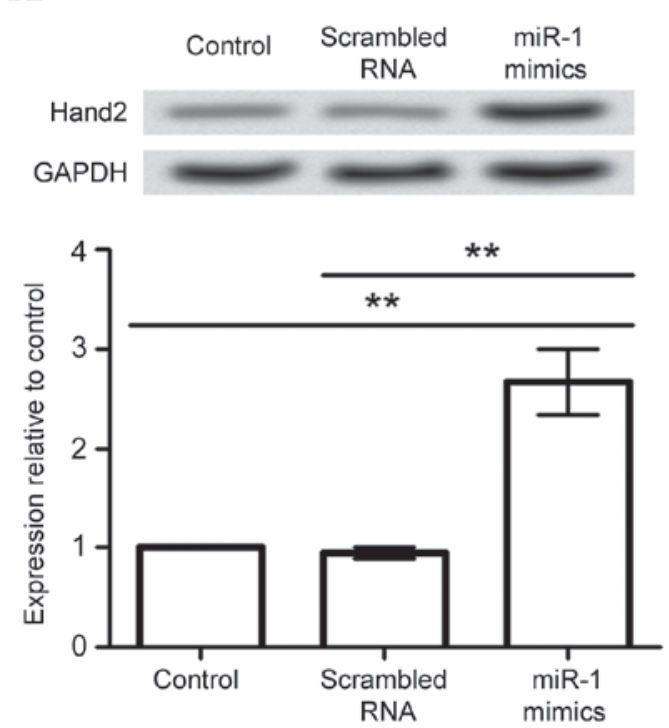

B
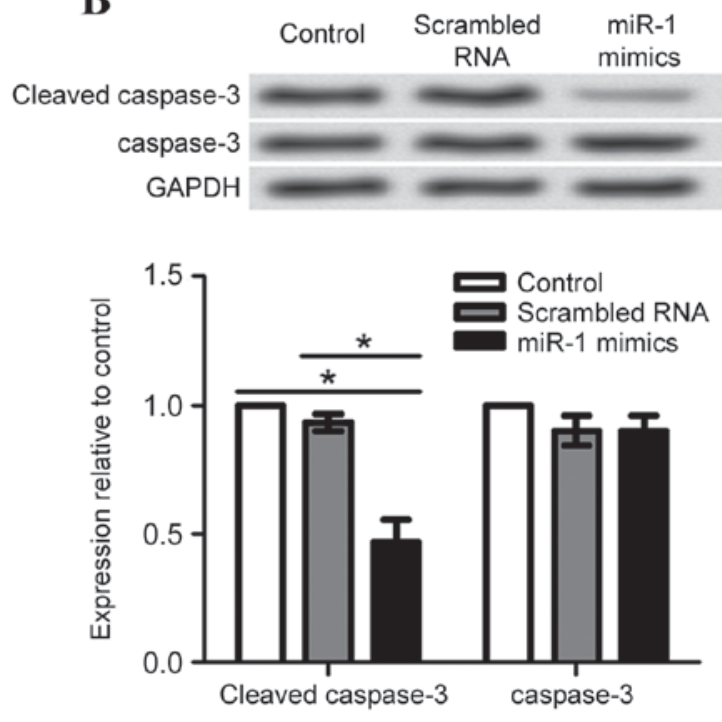

Figure 5. Effect of miR-1 overexpression on Hand2 and caspase-3 protein expression levels. Differentiated P19 cells were untransfected, or transfected with scrambled RNA or with miR-1 mimics. (A) Hand2 protein expression and (B) caspase-3 protein activity was assessed by western blot, with quantification relative to GAPDH. ${ }^{*} \mathrm{P}<0.05$ and ${ }^{* *} \mathrm{P}<0.01$, with comparisons indicated by lines. miR-1, microRNA-1; Hand2, heart and neural crest derivatives expressed transcript 2 .

days 5 and 10 (P>0.05; Fig. 1). These results demonstrated that the P19 cells were successfully differentiated into cardiomyocytes in the present study.

miR-1 expression in differentiated P19 cells. Endogenous miR-1 mRNA expression was significantly decreased in differentiated P19 cells compared with undifferentiated cells $(\mathrm{P}<0.05$; Fig. 2A). Following transfection of differentiated cells with siRNAs, miR-1 mimic and scramble, for $24 \mathrm{~h}$, miR-1 mRNA expression was analyzed to verify whether the transfection experiment was successful. The results demonstrated that miR-1 mRNA levels were significantly increased following transfection with the miR-1 mimic, compared with both transfected cells and cells transfected with control scrambled RNA ( $\mathrm{P}<0.05$; Fig. 2B).

miR-1 overexpression increases $P 19$ cell viability. To assess the effect of miR-1 overexpression on cell viability, viable cells were measured by MTT assay (Fig. 3). The results demonstrated that the number of viable cells was increased in a time-dependent manner in the P19 cells transfected with miR-1 mimic compared with the cells transfected with scrambled RNA control ( $\mathrm{P}<0.01$; Fig. 3$)$, suggesting that miR-1 overexpression may promote P19 cell proliferation.

miR-1 overexpression suppresses P19 cell apoptosis. To assess the effect of miR-1 overexpression on cell apoptosis in differentiated P19 cells, apoptotic cells were measured using an Annexin V-FITC labeling assay (Fig. 4). The mean percentage of early-stage apoptotic cells was significantly decreased when miR-1 was overexpressed (6.13\%), compared with the untransfected or scrambled RNA-transfected control cells (14.2 and $12.3 \%$, respectively; $\mathrm{P}<0.01$; Fig. 4).

Effect of miR-1 overexpression on Hand2 and caspase-3 expression. In order to investigate the possible mechanism of 
miR-1 in cardiomyocytes, expression of Hand2 and caspase-3 proteins was analyzed in differentiated P19 cells following transfection with miR-1 mimic and scrambled RNA. Hand2 protein expression levels were significantly increased by miR-1 overexpression, compared with the untransfected cells and cells transfected with scrambled RNA ( $\mathrm{P}<0.01$; Fig. 5A). By contrast, caspase-3 cleavage was significantly decreased by miR-1 overexpression, compared with the untransfected cells and cells transfected with scrambled RNA ( $\mathrm{P}<0.05$; Fig. 5B).

\section{Discussion}

Previous studies have demonstrated the importance of miRNAs in the regulation of heart development, including miR-1 and miR-133 (16), however, few studies have explored the potential role of miR-1 in P19 differentiated cardiomyocytes. In the present study, expression of miR-1 was evaluated in cardiomyocyte-differentiated and undifferentiated P19 cells, and its effect on the viability and apoptosis of cardiomyocyte-differentiated P19 cells was examined.

In agreement with previous studies (17-20), the present study confirmed that following treatment of P19 cells with DMSO, mRNA expression levels of the GATA4 and Nkx2-5 differentiation markers were significantly increased compared with untreated P19 cells (Fig. 1), indicating that P19 cells were successfully induced towards cardiomyocyte differentiation. When the differentiated P19 cells were examined, a significant decrease in endogenous miR-1 expression was observed compared with the undifferentiated cells (Fig. 2), suggesting an association between miR-1 expression levels and P19 cell differentiation state. The expression of miR-1 in P19 cells has not been previously reported. However, Thomson et al (21) demonstrated that miR-1 and miR-133 were involved in the regulation of P19 embryonal teratocarcinoma at the post-transcriptional level. The current study suggests that abnormal expression of miR-1 may be associated with the cardiomyocyte differentiation of P19 cells.

Consequently, the effect of miR-1 overexpression on cell viability and apoptosis in cardiomyocyte-differentiated P19 cells was assessed. miR-1 upregulation in skeletal muscle has been demonstrated to be positively correlated with muscle proliferation and differentiation (22). By contrast, miR-1 results in suppressed cardiomyocyte apoptosis by targeting HSP60 and caspase-9 (9). Similarly, lung cancer cell apoptosis is suppressed by upregulation of miR-1 (23). In the present study, cardiomyocyte-differentiated P19 cell viability was increased while apoptosis was suppressed by miR-1 overexpression, suggesting that miR-1 may be important in cardiac cell development by regulating proliferation and apoptosis.

The current study demonstrated that miR-1 overexpression resulted in increased Hand 2 expression but decreased caspase-3 cleavage in cardiomyocyte-differentiated P19 cells (Fig. 5). Hand 2 is asymmetrically expressed in the developing ventricular chambers and is important in cardiac morphogenesis (24). Yelon et al (25) demonstrated that Hand2 served parallel roles to cell proliferation and apoptosis in the heart development of zebrafish, and Olson (26) demonstrated that Hand 2 was preferentially expressed in the derivative of the heart field. Hence, it was hypothesized that miR-1 upregulation may contribute to cardiac differentiation in P19 cells. Caspase-3 is a cell apoptosis executor and its high expression indicates a high percentage of apoptotic cells $(27,28)$. Izarra et al (16) demonstrated that miR-1 overexpression results in reduced cell apoptosis in pluripotent stem cells during cardiac differentiation. In addition, Shan et al (29) demonstrated that caspase-3 levels are decreased by miR-1 upregulation in a rat model of myocardial infarction. The present study indicates that miR-1 suppresses cell apoptosis in cardiomyocyte-differentiated P19 cells by decreasing caspase-3 cleavage.

In conclusion, the present study revealed that miR-1 regulates heart development through the cell proliferation and apoptosis processes, by increasing Hand 2 expression and suppressing caspase-3 cleavage in cardiomyocyte-differentiated P19 cells. The present study may provide a theoretical basis for the role of miR-1 in regulating cardiomyocytes development and may indicate miR-1 as a potential target in the therapeutic treatment of CHD in infants. Further experimental studies are required to fully understand the mechanism of miR-1 in the regulation of the P19 cells and the heart development.

\section{References}

1. Al Mazrouei SK, Moore J, Ahmed F, Mikula EB and Martin GR: Regional implementation of newborn screening for critical congenital heart disease screening in Abu Dhabi. Pediatr Cardiol 34: 1299-1306, 2013.

2. Dale MT, Solberg O, Holmstrøm H, Landolt MA, Eskedal LT and Vollrath ME: Mothers of infants with congenital heart defects: Well-being from pregnancy through the child's first six months. Qual Life Res 21: 115-122, 2012.

3. Ratanachu-Ek S and Pongdara A: Nutritional status of pediatric patients with congenital heart disease: Pre- and post cardiac surgery. J Med Assoc Thai 94 (Suppl 3): S133-S137, 2011.

4. Moons P, Bovijn L, Budts W and Gewillig M: Abstract 1866: Actual prospects to survive into adulthood in patients with congenital heart disease. Circulation 120 (Suppl): S561, 2009.

5. Song R: Expression and function of small non-coding RNAs in the mouse testis. PhD dissertation. University of Nevada. ProQuest/UMI, Publication no. AAT 3472784, Reno, NV, 2011.

6. Moll R, Sievers E, Hämmerling B, Schmidt A, Barth M, Kuhn C, Grund C, Hofmann I and Franke WW: Endothelial and virgultar cell formations in the mammalian lymph node sinus: Endothelial differentiation morphotypes characterized by a special kind of junction (complexus adhaerens). Cell Tissue Res 335: 109-141, 2008.

7. Kawashima K and Koshimizu U: Method for proliferation cardiomyocytes using micro-rna. US Patent 20140213634 A1. Filed April 4, 2014; issued July 31, 2014.

8. L'Honore A, Rana V, Arsic N, Franckhauser C, Lamb NJ and Fernandez A: Identification of a new hybrid serum response factor and myocyte enhancer factor 2-binding element in MyoD enhancer required for MyoD expression during myogenesis. Mol Biol Cell 18: 1992-2001, 2007.

9. Xu C, Lu Y, Pan Z, Chu W, Luo X, Lin H, Xiao J, Shan H, Wang $\mathrm{Z}$ and Yang B: The muscle-specific microRNAs miR-1 and miR-133 produce opposing effects on apoptosis by targeting HSP60, HSP70 and caspase-9 in cardiomyocytes. J Cell Sci 120: 3045-3052, 2007.

10. Grobe JL, Mecca AP, Lingis M, Shenoy V, Bolton TA, Machado JM, Speth RC, Raizada MK and Katovich MJ: Prevention of angiotensin II-induced cardiac remodeling by angiotensin-(1-7). Am J Physiol Heart Circ Physiol 292: H736-H742, 2007.

11. McBurney MW, Jones-Villeneuve EM, Edwards MK and Anderson PJ: Control of muscle and neuronal differentiation in a cultured embryonal carcinoma cell line. Nature 299: 165-167, 1982 . 
12. Choi SC, Choi JH, Shim WJ and Lim DS: P19 Embryonal carcinoma cells: A new model for the study of endothelial cell differentiation. Biotechnol Lett 30: 1169-1175, 2008.

13. Paquin J, Danalache BA, Jankowski M, McCann SM and Gutkowska J: Oxytocin induces differentiation of P19 embryonic stem cells to cardiomyocytes. Proc Natl Acad Sci USA 99: 9550-9555, 2002.

14. Arseculeratne SN, Atapattu DN, Kumarasiri R, Perera D, Ekanayake D and Rajapakse J: The use of MTT [3-(4, 5-dimethyl-2-thiazolyl)-2,5-diphenyl-2H-tetrazolium bromide]reduction as an indicator of the effects of strain-specific, polyclonal rabbit antisera on Candida albicans and C. Indian J Med Microbiol 25: 267-271, 2007.

15. Livak KJ and Schmittgen TD: Analysis of relative gene expression data using real-time quantitative PCR and the 2(-Delta Delta C(T)) Methods. Methods 25: 402-408, 2001.

16. Izarra A, Moscoso I, Cañón S, Carreiro C, Fondevila D, Martín-Caballero J, Blanca V, Valiente I, Díez-Juan A and Bernad A: miRNA-1 and miRNA-133a are involved in early commitment of pluripotent stem cells and demonstrate antagonistic roles in the regulation of cardiac differentiation. J Tissue Eng Regen Med: Dec 10, 2014 (Epub ahead of print).

17. Brown CO III, Chi X, Garcia-Gras E, Shirai M, Feng XH and Schwartz RJ: The cardiac determination factor, Nkx2-5, is activated by mutual cofactors GATA- 4 and Smad1/4 via a novel upstream enhancer. J Biol Chem 279: 10659-10669, 2004.

18. Haveri H, Ashorn M, Iltanen S, Wilson DB, Andersson LC and Heikinheimo M: Enhanced expression of transcription factor GATA4 in inflammatory bowel disease and its possible regulation by TGF-beta1. J Clin Immunol 29: 444-453, 2009.

19. Zhou Y and Xiao-Yu HE: Expression of the transcription factor GATA-4 in human heart development. J Med Postg, 2008.

20. Zaglia T, Dedja A, Candiotto C, Cozzi E, Schiaffino S and Ausoni S: Cardiac interstitial cells express GATA4 and control dedifferentiation and cell cycle re-entry of adult cardiomyocytes. J Mol Cell Cardiol 46: 653-662, 2009.
21. Thomson JM, Newman M, Parker JS, Morin-Kensicki EM, Wright $\mathrm{T}$ and Hammond SM: Extensive post-transcriptional regulation of microRNAs and its implications for cancer. Gene Dev 20: 2202-2207, 2006.

22. Chen JF, Mandel EM, Thomson JM, Wu Q, Callis TE, Hammond SM, Conlon FL and Wang DZ: The role of microRNA-1 and microRNA-133 in skeletal muscle proliferation and differentiation. Nat Genet 38: 228-233, 2006.

23. Nasser MW, Datta J, Nuovo G, Kutay H, Motiwala T, Majumder S, Wang B, Suster S, Jacob ST and Ghoshal K: Down-regulation of micro-RNA-1 (miR-1) in lung cancer. Suppression of tumorigenic property of lung cancer cells and their sensitization to doxorubicin-induced apoptosis by miR-1. J Biol Chem 283: 33394-33405, 2008.

24. VanDusen NJ, Casanovas J, Vincentz JW, Firulli BA, Osterwalder M, Lopez-Rios J, Zeller R, Zhou B, Grego-Bessa J, De La Pompa JL, et al: Hand2 is an essential regulator for two Notch-dependent functions within the embryonic endocardium. Cell Rep 9: 2071-2083, 2014.

25. Yelon D, Ticho B, Halpern ME, Ruvinsky I, Ho RK, Silver LM and Stainier DY: The bHLH transcription factor hand2 plays parallel roles in zebrafish heart and pectoral fin development. Development 127: 2573-2582, 2000.

26. Olson EN: Gene regulatory networks in the evolution and development of the heart. Science 313: 1922-1927, 2006.

27. Sun J, Shen X, Xie B, Zhong YS, Lu Q and Sun Y: Effects of high glucose on apoptosis of human umbilical vein endothelial cells and expression of Caspase-3. J Shang Jiaotong Univ 34: 1709-1713, 2014.

28. Isa SA, Mainwaring LS, Webb R and Thomas AW: The non-genomic effects of high doses of Rosiglitazone on cell growth and apoptosis in cultured monocytic cells. Bayero J Pure Appl Sci 2: 1-8, 2009.

29. Shan ZX, Lin QX, Fu YH, Deng CY, Zhou ZL, Zhu JN, Liu XY, Zhang YY, Li Y, Lin SG and Yu XY: Upregulated expression of $\mathrm{miR}-1 / \mathrm{miR}-206$ in a rat model of myocardial infarction. Biochem Biophys Res Commun 381: 597-601, 2009. 